\title{
Deriving sea-ice thickness and ice types in the Sea of Okhotsk using dual-frequency airborne SAR (Pi-SAR) data
}

\author{
Takeshi Matsuoka, ${ }^{1}$ Seino Uratsuka, ${ }^{2}$ Makoto Satake, ${ }^{2}$ Akitsugu Nadai, ${ }^{2}$ Toshiniko Umehara, ${ }^{2}$ \\ Hideo Maeno, ${ }^{2}$ Hiroyuki Wakabayashi,${ }^{3}$ Fuminiko Nishio, ${ }^{4}$ Yasushi Fukamachi ${ }^{5}$ \\ ${ }^{1}$ Okinawa Subtropical Environment Remote Sensing Center, Communications Research Laboratory, 4484 Aza-Onna, Onna, \\ Kunigami, Okinawa 904-0411, Japan \\ ${ }^{2}$ Applied Research and Standards Division, Communications Research Laboratory, Nukui-kita 4-2-1, Koganei, Tokyo 184-8795, Japan \\ ${ }^{3}$ Earth Observation Research Center, National Space Development Agency of Japan, Harumi 1-8-10, Chuo-ku, Tokyo 104-6023, Japan \\ ${ }^{4}$ Center for Earth Remote Sensing, Chiba University, 1-33 Tayoi-chou, Inage-ku, Chiba 263-8522, Japan \\ ${ }^{5}$ Institute of Low Temperature Science, Hokkaido University, Sapporo, Hokkaido 060-0819, Japan
}

\begin{abstract}
Dual-frequency, multi-polarization airborne synthetic aperture radar (Pi-SAR; developed by the Communications Research Laboratory and National Space Development Agency of Japan) observations of the seasonal sea-ice region off the Okhotsk coast of Hokkaido, Japan, were carried out in February 1999 using X- and L-band radar frequencies with a resolution of 1.5 and $3.0 \mathrm{~m}$. In conjunction with the SAR observations, the sea-ice thickness (draft) and velocity were measured by a moored Ice Profiling Sonar (IPS) and an Acoustic Doppler Gurrent Profiler (ADCP). Tracks of the sea ice passing over the IPS were estimated from the time series of the ADCP ice-velocity and -direction data. Along these tracks, the SAR backscattering coefficient profiles were compared with the IPS ice-draft profiles. The results showed that the L-band SAR backscattering profiles correlated well with the IPS ice-draft data, particularly in the thicker part (a few meters thick) of the rim of first-year ice, which had a large backscattering coefficient. Although the X-band SAR backscattering profiles did not correlate well with the IPS data, thin ice $(<10 \mathrm{~cm}$ thick) showed a large backscattering coefficient. The L-band SAR and IPS data did not distinguish thin ice from open water.
\end{abstract}

\section{INTRODUGTION}

The extent of the seasonal sea-ice zone and the sea-ice volume greatly affect the energy exchange between the atmosphere and the ocean. Thin sea ice, such as new and young ice $<0.3 \mathrm{~m}$ thick, is of critical significance in controlling the vigor of heat, salt and vapor fluxes at the ocean surface (Grenfell and others, 1992). Thus, detecting and classifying the thin ice using remote-sensing technology is of particular importance.

The Sea of Okhotsk is one of the most southerly seasonal sea-ice zones in the Northern Hemisphere. The sea ice extends to the eastern coast of Hokkaido, Japan, every winter, from January to March. The extent of sea ice in the Sea of Okhotsk is believed to be greatly influenced by global climatic change (Noda and others, 1996). In addition, the change in ice extent influences the downstream towards North America as well as the Okhotsk atmospheric response (Honda and others, 1999).

In ice-extent investigations so far, passive- and activemicrowave remote-sensing data (SSM/I, ERS-1/-2, JERS-1, RADARSAT) have provided horizontal distribution information on the Okhotsk sea ice. Matsuoka and others (2001) reported that a dual-frequency, multi-polarization airborne synthetic aperture radar (SAR) can provide qualitative information on ice types and thickness. However, ascertaining the ice volume is still difficult due to the lack of in situ data on ice types and thickness.

Together with the ice extent the ice thickness determines the response of the sea ice to climatic change. However, using submarine upwelling sonar measurements (reviewed in Wadhams and Comiso, 1992) and ship-based observations to measure thickness enables only a limited spatial coverage and temporal resolution. Recently, to estimate the sea-ice volume, an upward-looking Ice Profiling Sonar (IPS) and an Acoustic Doppler Gurrent Profiler (ADCP) were moored off the Okhotsk coast of Hokkaido. The measured time series of the ice-thickness (draft) and -velocity data showed the detailed ice characteristics in the Sea of Okhotsk (Fukamachi and others, 2000).

In conjunction with the IPS and ADCP observations, we carried out two airborne SAR observations at a 20 hour interval over the location of the IPS in February 1999. In this paper we report the relationship between the IPS icedraft profile and the SAR backscattering profiles that were estimated from the ADCP ice-velocity and -direction data.

\section{OBSERVATIONS}

\section{Test site}

Figure 1 shows a map of the test site. The airborne SAR and the moored sonar observation data were obtained simultaneously off the Okhotsk coast of Hokkaido. The SAR observations were carried out twice, at 16:30 Japanese Standard Time (JST) on 23 February and at 12:45 JSTon 24 February 1999. The weather conditions during this period were relatively calm. The 


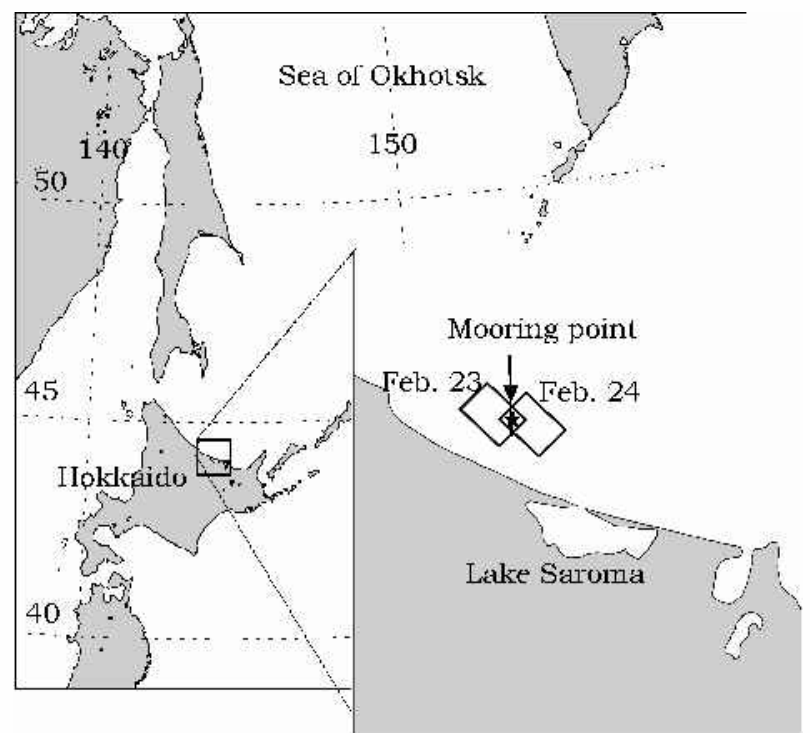

Fig. 1. Map of test site. The two rectangles in the enlarged map are 23 and 24 February 1999 Pi-SAR observation areas. The marked mooring point is the IPS and ADCP location. average wind speed was $3.5 \mathrm{~m} \mathrm{~s}^{-1}$ coming mainly from the west. The air temperature ranged from $-12^{\circ}$ to $0^{\circ} \mathrm{C}$ at the nearest ground meteorological station, which was $12 \mathrm{~km}$ from the IPS.

\section{Airborne SAR}

The dual-frequency, multi-polarization airborne SAR (PiSAR) was developed by the Communications Research Laboratory and National Space Development Agency of Japan. The frequencies are X- and L-band with resolutions of 1.5 and $3.0 \mathrm{~m}$. The ground-range swath is approximately $15 \mathrm{~km}$, and typical incidence angles range from $20^{\circ}$ to $60^{\circ}$. The Pi-SAR has polarimetric (X-and L-band) and interferometric (X-band) functions (Kobayashi and others, 2000). In this study we discuss the backscattering magnitude of $\mathrm{HH}, \mathrm{VV}$ and $\mathrm{HV}$ polarization channels since polarimetric calibration is still ongoing. A polarimetric analysis will be carried out in the near future.

The observation areas are shown as rectangles in the enlarged map in Figure 1. Figure 2 shows the Pi-SAR images obtained on 23 and 24 February, as a color composite of the HH (red), VV (green) and HV (blue) channels.
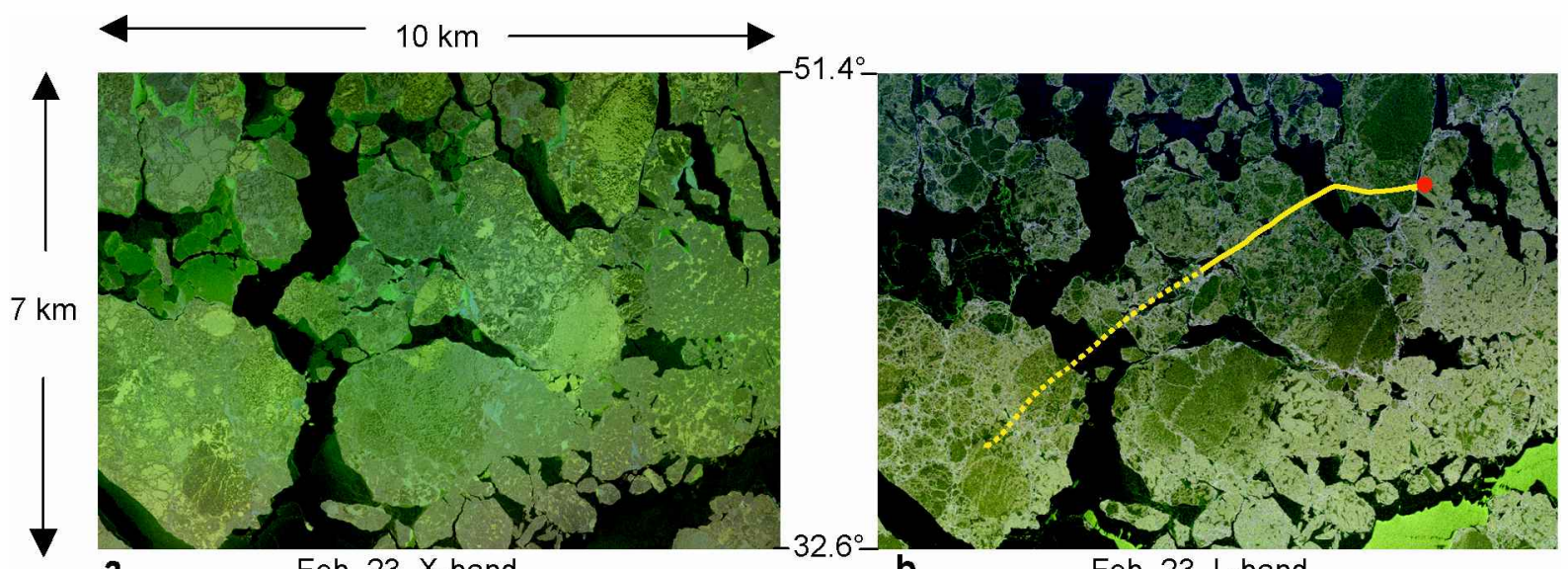

a

Feb. 23, X-band

b

Feb. 23, L-band
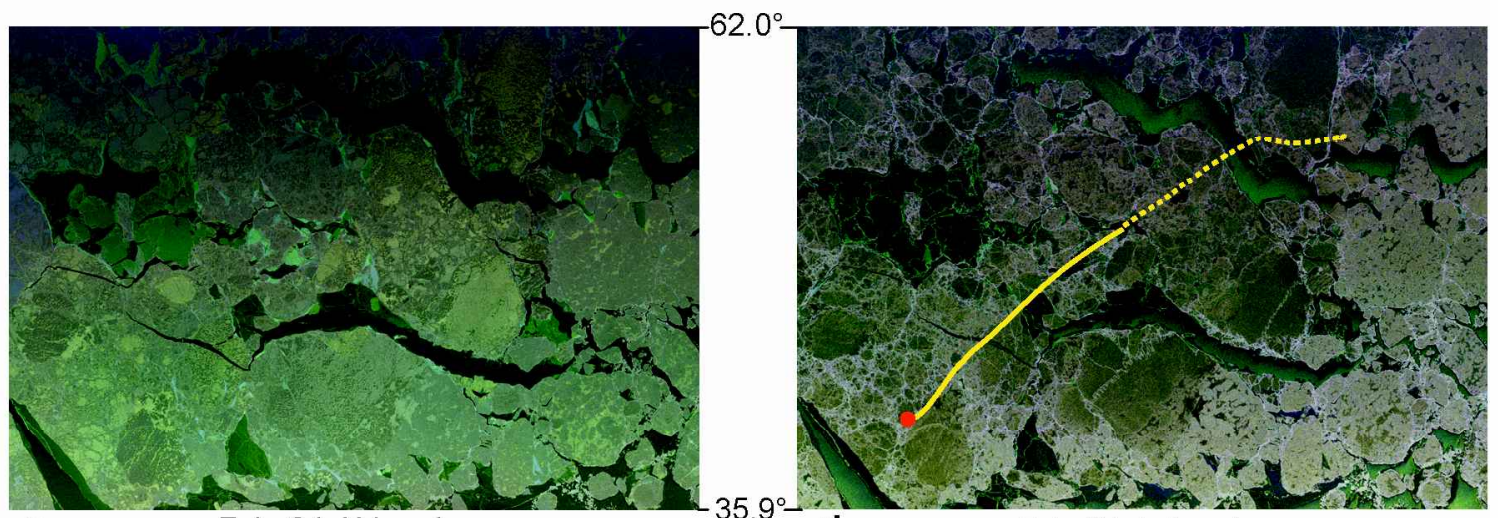

C

Feb. 24, X-band

$35.9^{\circ}-$

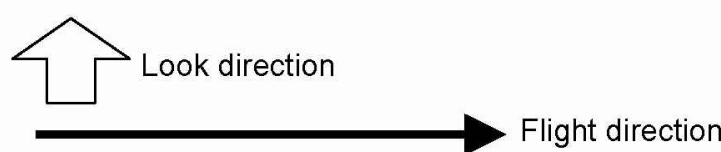

$\mathrm{N}$

Feb. 24, L-band

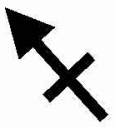

Fig. 2. Pi-SAR images (7 km in ground range, $10 \mathrm{~km}$ in azimuth) obtained on 23 and 24 February, as a color composite of the HH (red), $V V$ (green) and $H V$ (blue) channels. Numbers in the center are the incidence angles. Moored IPS location (red point) and estimated track of sea ice that passed over the IPS (yellow lines) are superimposed in $(b)$ and $(d)$. 
The backscattering power (brightness in the image) from thin sea ice and first-year ice is dominated by the ice surface roughness related to the radar wavelength and the dielectric constant that was determined by the salinity of the sea ice.

Although the sea ice drifted eastwards about $7.5 \mathrm{~km}$ during the 2 day observation (20 hours), the relative arrangement of the ice barely changed because of the calm weather during this period.

\section{IPS and ADGP}

The IPS and ADCP were moored about $10 \mathrm{~km}$ off the Okhotsk coast, where the water is about $60 \mathrm{~m}$ deep. The moored IPS was located around $44^{\circ} 20^{\prime} \mathrm{N}, 144^{\circ} 39^{\prime} \mathrm{E}$, and the time series of the sea-ice draft data was obtained from early February to late March. The horizontal spot on the IPS beam was about $1.5 \mathrm{~m}$, and the ice-draft uncertainty was $0.1-0.2 \mathrm{~m}$. This value depends on the accuracy of the temperature-dependent sound-speed estimation in the water (Melling and others, 1995). The time series of the seaice velocity data was obtained by the ADCP. The accuracy of the ice velocity was $0.2 \mathrm{~cm} \mathrm{~s}^{-1}$. The track of the sea ice passing over the IPS was estimated using the ADCP icevelocity data, and the track between the two SAR observations is superimposed on Figure $2 \mathrm{~b}$ and $\mathrm{d}$. The total
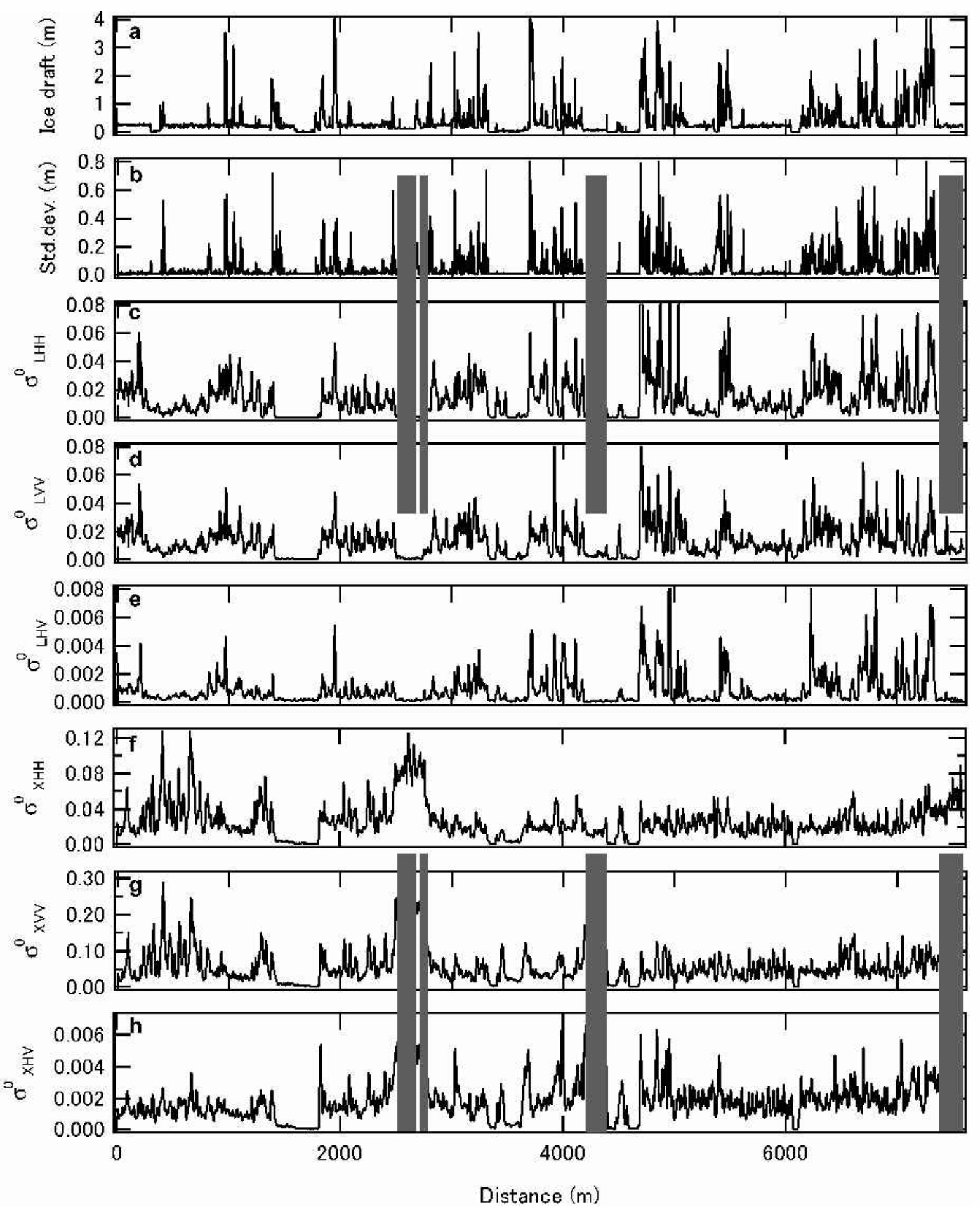

Fig. 3. A $7.6 \mathrm{~km}$ section of profiles from the observations by moored sonar and Pi-SAR: (a) IPS profile of ice draft; (b) profile of standard deviation of ice draft; (c) L-band HH, (d) L-bandVV, (e) L-band HV, (f) X-band HH, $(g) X$-bandVV, and $(h)$ $X$-band HV polarization SAR profiles of backscattering coefficient. Hatched areas indicate thin-ice areas. 
track distance measured over 20 hours was $7590 \mathrm{~m}$, and the average ice velocity was $10 \mathrm{~cm} \mathrm{~s}^{-1}$.

\section{RESULTS AND DISGUSSION}

\section{IPS and SAR profiles}

Figure 3a shows the topographic profile of the ice draft, which was converted from equal time intervals to equal space intervals using the ADCP ice-velocity data. The average ice draft was about $0.49 \mathrm{~m}$, and profile maximum is $4.77 \mathrm{~m}$. The standard deviation profile of the ice draft is shown in Figure 3b. It was derived from ice-draft data from five neighboring points at $0.5 \mathrm{~m}$ intervals. The profile shape had good agreement with the shape of the ice-draft profile. Large values for standard deviations and thick ice $(>1 \mathrm{~m})$ are often observed at the rim of ice floes. We concluded from these results that thick ice was formed by rafting and ridging at the rims of the ice.

Figure $3 \mathrm{c}-\mathrm{h}$ show the backscattering coefficient $\left(\sigma^{\circ}\right)$ profile of the estimated ice track (solid lines in Figure $2 \mathrm{~b}$ $(0-3600 \mathrm{~m})$ and $\mathrm{d}(3600-7600 \mathrm{~m}))$. The backscattering coefficient has incidence-angle dependence. We corrected for the dependence by comparing the backscattering coefficients of the observed locations that had different incidence angles in 2 day SAR observations. The correction coefficients were $<0.4 \mathrm{~dB}$ per degree in all polarization channels of the L-band and $<0.2 \mathrm{~dB}$ per degree in all polarization channels of the X-band around an incidence angle of $45^{\circ}$.

Figure $3 \mathrm{e}$ and $\mathrm{g}$ show the backscattering coefficient profiles of the L-band HVand the X-band VVat a corrected $45^{\circ}$ incidence angle. The SAR data were averaged to $12.5 \mathrm{~m}$ (5 pixels for the L-band, 10 pixels for the X-band) for the direction perpendicular to the ice track, and to a $12.5 \mathrm{~m}$ running mean with $2.5 \mathrm{~m}$ intervals for the direction of the ice track. The L-band profile had good agreement with the ice draft and the standard deviation. The correlation coefficient between the backscattering coefficient of the Lband HV channel and the ice-draft profile reached 0.64 , which was the highest correlation with the draft data for the three L-band channels $(0.46$ at $\mathrm{HH}, 0.42$ at VV, 0.64 at HV). There were much higher correlations between the profiles of SAR backscattering and ice-draft data near the start and the end than in the middle of the estimated ice track. This suggests that the difference in the data-acquisition points of SAR and IPS was largest in the middle of the estimated ice track.

The backscattering of cross-polarization is mainly caused by surface multiple scattering and volume scattering from sea ice and is not related directly to the ice draft. This suggests that the surface roughness of thick sea ice resulting from ridging and rafting caused the large backscattering.

The profile of the backscattering coefficient of X-band VV had almost no correlation with the ice-draft data. However, there was good correlation between them in the openwater area, where the $\mathrm{X}-\mathrm{VV}$ backscattering was extremely small. Interestingly, large backscattering was clearly observed in the thin-sea-ice areas (hatched areas in Fig. 3), which were not distinguished from the open water in the L-band SAR and IPS data.

\section{Ice-draft estimation using SAR data}

The good correlation between the ice-draft profile and the
L-band HV SAR backscattering coefficient profile (Fig. 3a and e) enables us to estimate the horizontal distribution of the ice draft using the SAR data. Figure 4 shows the scatter plot of the backscattering coefficient in decibels vs the icedraft data on a log scale. The backscattering coefficient was simply approximated by the regression line in Figure 4. The regression line is described as follows:

$$
\sigma_{\mathrm{LHV}}^{\circ}=7.3 \log (d)-28.4(\mathrm{~dB}),
$$

where $d$ is the ice draft in meters. The dispersion of the backscattering values from the regression line was mainly caused by small differences in the data-acquisition points of the SAR and IPS. The backscattering coefficient for the change in the ice draft ranged more widely in the L-band $\mathrm{HV}$ channel than in the other polarization channels.

We converted the SAR backscattering image of the Lband $\mathrm{HV}$ channel in Figure $2 \mathrm{~b}$ into the estimated ice-draft image that is shown in Figure 5a using Equation (1). This image suggests that the rim of ice floes has large ice-draft values. Ice thicker than $1 \mathrm{~m}$ in this image reached $15 \%$ of the area, containing more than one-third of the fresh-water volume in this area.

\section{Glassification of ice types}

Distinguishing open water and thin ice $<15 \mathrm{~cm}$ thick using Lband SAR data is still difficult because the backscattering power from open water was comparable to that from thin ice. Also, the values were near the noise floor at a relatively large incidence angle of $45^{\circ}$. The noise floors in the SAR observations were estimated to be less than $-40 \mathrm{~dB}$ at L-HV, $-34 \mathrm{~dB}$ at L-HH and L-VV, $-38 \mathrm{~dB}$ at X-HV and $-28 \mathrm{~dB}$ at X$\mathrm{HH}$ and $\mathrm{X}-\mathrm{VV}$ in backscattering coefficient. However, the $\mathrm{X}$ band VV channel backscattering profile shown in Figure $3 g$ suggests that there was large backscattering from the thin-ice area (over $18 \mathrm{~dB}$ larger than the backscattering from open water). Also, a large polarization ratio $(\mathrm{VV} / \mathrm{HH})$ in $\mathrm{X}$-band backscattering from thin ice was reported by Matsuoka and others (2001) in the same Pi-SAR experiments.

In the case of thin ice and first-year ice, the surface roughness and the salinity play the dominant role in determining

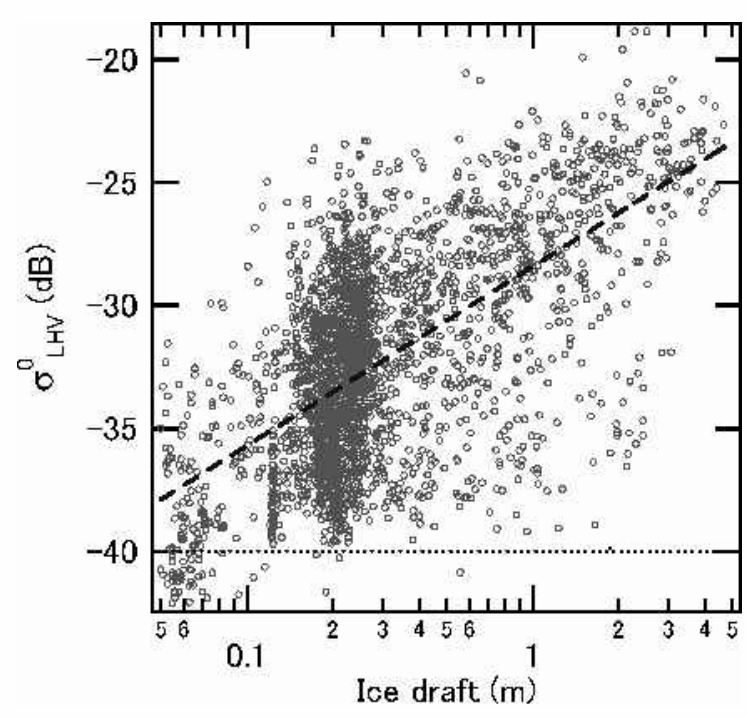

Fig. 4. Scatter plot of L-band HV polarization backscattering coefficient in decibels vs ice-draft data on log scale. Dashed line is regression line. The noise floor was less than $-40 \mathrm{~dB}$ (dotted line). 


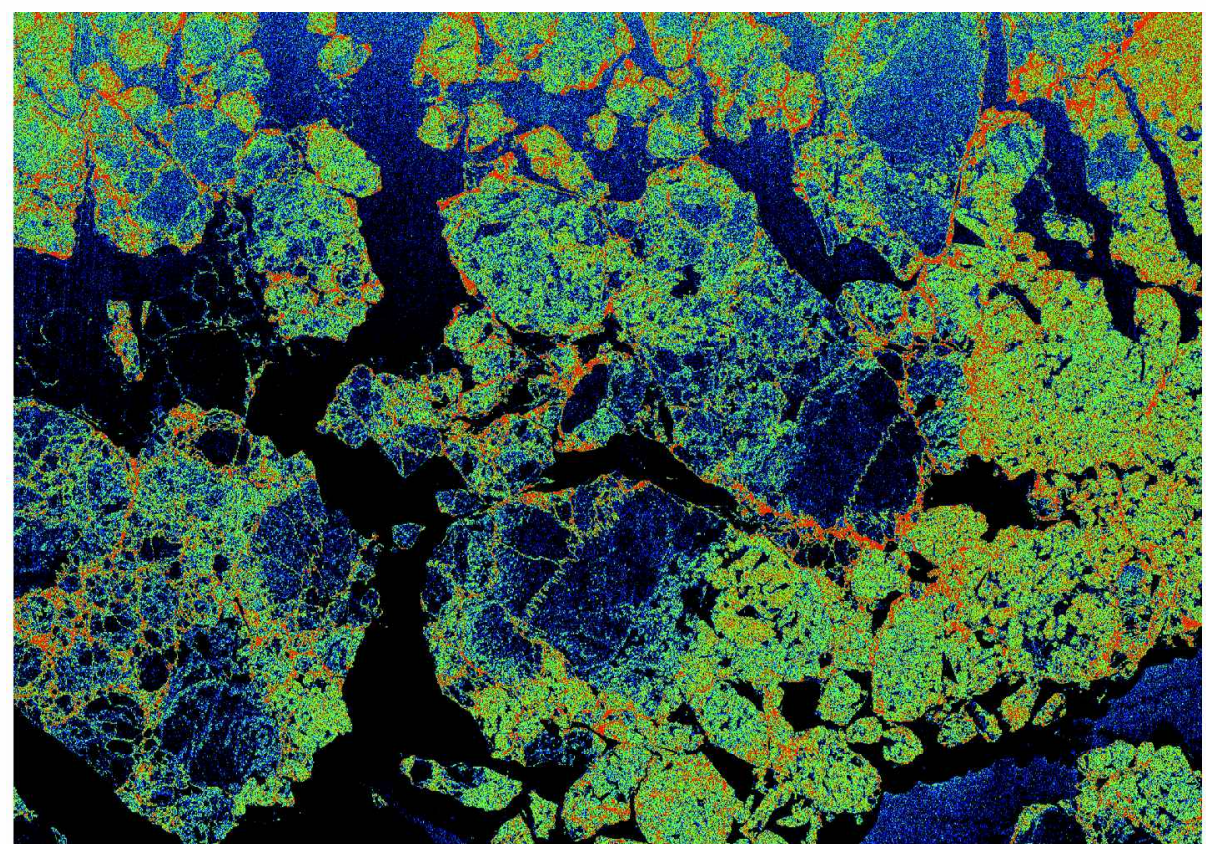

a
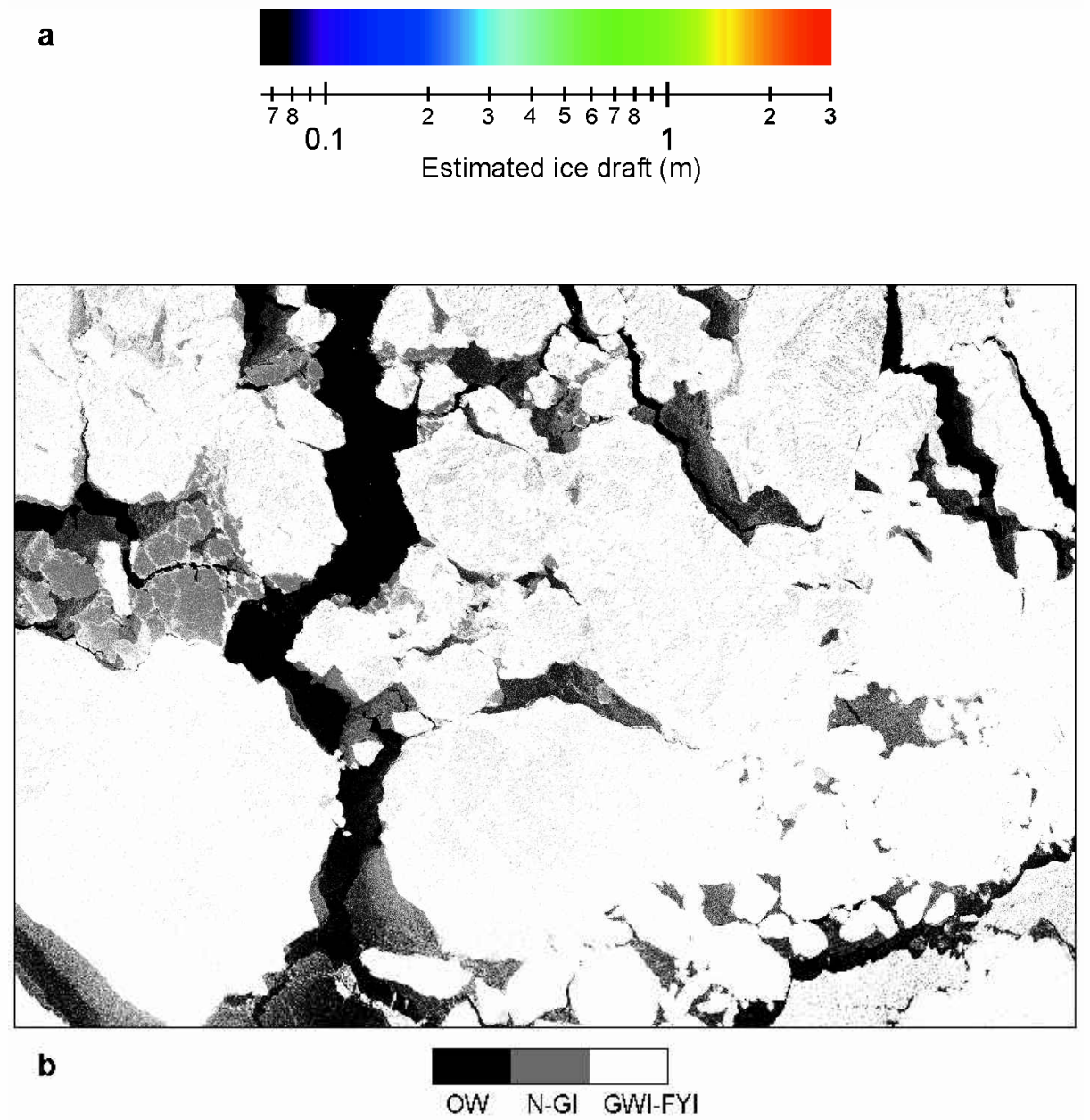

Fig. 5. (a) Estimated ice-draft image converted from the backscattering coefficient image of the L-band HV channel. (b) Classification of three ice categories: OW is open water, $\mathcal{N}$-GI is nilas and gray ice, and GWI-FYI is gray-white ice and firstyear ice.

the backscattering properties. Previous research showed that the measured rms roughness of sea ice thinner than $15 \mathrm{~cm}$ was mostly $<0.1 \mathrm{~cm}$ (Onstott, 1992). According to the Fraunhofer criterion for a surface to be considered smooth (Ulaby and others, 1982), the value of $0.1 \mathrm{~cm}$ is smooth enough to reduce the backscattering power for the large wavelength of the Lband and is not for the X-band. First-order model calcu- lations for the relatively smooth surface sea ice showed that the polarization ratio increases as the rms roughness decreases and as the salinity increases (Winebrenner and others, 1989).

These results allowed classification of the ice types using the X-band VV and HH data together with the L-band data. Ice types were classified into the World Meteorological 


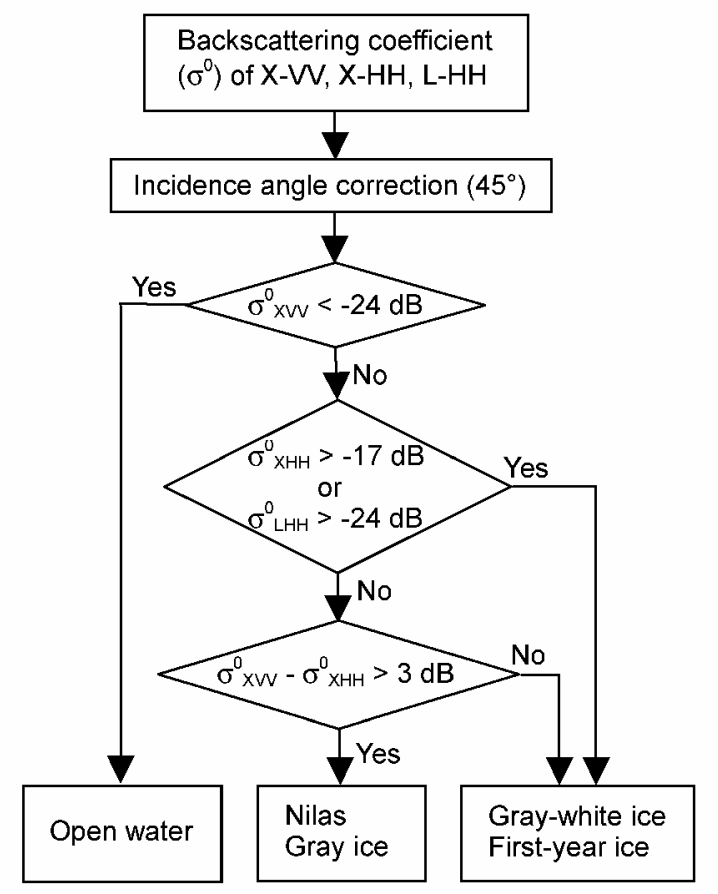

Fig. 6. Example block diagram of ice-type classification algorithm.

Organization's standard categories, based on the ice thickness (WMO, 1970). The classification algorithm derived from comparing the ice-draft data and the SAR data is shown in Figure 6. The SAR channels used in classification and the threshold values were chosen by picking the training sets along the estimated ice track. The estimated accuracy of the classification was $>90 \%$ in each ice (surface) type. Open water was detected using the X-band VV channel; graywhite ice and first-year ice thicker than $15 \mathrm{~cm}$ were detected using the $\mathrm{X}$-band $\mathrm{HH}$ and L-band $\mathrm{HH}$ channels; and thin ice, such as nilas and gray ice less than $15 \mathrm{~cm}$, was detected using the $\mathrm{X}$-band polarization ratio. Figure $5 \mathrm{~b}$ shows the classified ice. We can clearly distinguish the thin-ice areas between the open water and first-year ice. The image showed $13 \%$ open water, $8 \%$ thin ice (nilas and gray ice) and $79 \%$ first-year ice (gray-white ice and first-year ice).

\section{GONGLUSION}

To investigate sea-ice types and thickness distributions in the Sea of Okhotsk near the northeastern coast of Hokkaido, we carried out Pi-SAR observations twice in February 1999. The ice-draft and velocity data obtained using an upwardlooking IPS and an ADCP moored into the sea $10 \mathrm{~km}$ off the Okhotsk coast of Hokkaido were used to acquire in situ seaice thickness data. The ice-draft profile and the profile of the standard deviation of the ice draft along the estimated ice track derived from the ADCP ice-velocity data suggested that the ice thicker than $1 \mathrm{~m}$ was formed by rafting and ridging at the rim of ice floes.

We compared the ice-draft profile and SAR backscattering coefficient profiles along the estimated ice track. The results showed that the backscattering coefficient profile of the L-band $\mathrm{HV}$ channel agreed well with the ice- draft profile. The estimated ice-draft image converted from the SAR image indicated clearly that the thick sea ice was mainly formed at the ice-floe rims. Large backscattering from thin ice, such as nilas and gray ice, was revealed in the $\mathrm{X}$-band backscattering profile. The ice types were classified using the $\mathrm{X}$-band $\mathrm{VV}$ and $\mathrm{HH}$ backscattering profile data together with the L-band data. The classification results clearly showed that there was a certain amount of thin ice between open water and first-year ice.

The Pi-SAR proved to be a very effective method for identifying sea-ice characteristics, such as the thickness distribution of first-year ice, which enables us to understand the fresh-water flux in the sea, and the horizontal distribution of thin ice, which enables us to understand the heat exchange between the ocean and the atmosphere. Further studies on detailed ice-type identification will be conducted using the polarimetric functions of the Pi-SAR in the near future.

\section{ACKNOWLEDGEMENTS}

The authors would like to thank M. Wakatsuchi of the Institute of Low Temperature Science, Hokkaido University, for providing the IPS and ADCP data which were acquired in a research project funded by the Japan Science and Technology Corporation.

\section{REFERENCES}

Fukamachi, Y., G. Mizuta, K. I. Ohshima, M. Aota and M. Wakatsuchi. 2000. Mooring measurement of ice thickness off Yubetsu, Hokkaido. In International Symposium on Atmosphere-Ocean-Cryosphere Interaction in the Sea of Okhotsk and the Surrounding Environment. Proceedings. Sapporo, Hokkaido University. Institute of Low Temperature Science, 32-33.

Grenfell, T. C. and 7 others. 1992. Considerations for microwave remote sensing of thin sea ice. In Carsey, F. D. and 7 others, eds. Microwave remote sensing of sea ice. Washington, DC, American Geophysical Union, 291-301. (Geophysical Monograph Series 68.

Honda, M., K. Yamazaki, H. Nakamura and K. Takeuchi. 1999. Dynamic and thermodynamic characteristics of atmospheric response to anomalous seaice extent in the Sea of Okhotsk. F. Climate, 12(12), 3347-3358.

Kobayashi,T. and 10 others. 2000. Airborne dual-frequency polarimetric and interferometric SAR. IEICE Trans. Commun., E83-B (9), 1945-1954.

Matsuoka, T. and 9 others. 2001. CRL/NASDA airborne SAR (Pi-SAR) observations of sea ice in the Sea of Okhotsk. Ann. Glaciol., 33, 115-119.

Melling, H., P. H. Johnston and D. A. Riedel. 1995. Measurements of the underside topography of sea ice by moored subsea sonar. 7. Atmos. Oceanic Technol., 12(3), 589-602.

Noda, A., S. Nakagawa, T. Motoi, S. Yukimoto and T. Tokioka.1996. Global warming induced by $\mathrm{CO}_{2}$ and the Okhotsk Sea. 7. Remote Sensing Soc. Jpn, 16(2), 3-13.

Onstott, R. 1992. SAR and scatterometer signatures of sea ice. In Carsey, F. D. and 7 others, eds. Microwave remote sensing of sea ice. Washington, DC, American Geophysical Union, 73-104. (Geophysical Monograph Series 68.)

Ulaby, F.T., R. K. Moore and A. K. Fung. 1982. Microwave remote sensing, active and passive. Vol. 2. Radar remote sensing and surface scattering and emission theory. Reading, MA, Addison-Wesley Publishing Co.

Wadhams, P. and J. C. Comiso. 1992. The ice thickness distribution inferred using remote sensing techniques. In Carsey, F. D. and 7 others, eds. Microwave remote sensing of sea ice. Washing ton, DC, American Geophysical Union, 375-383. (Geophysical Monograph Series 68.)

Winebrenner, D. P., L. Tsang, B. Wen and R. West. 1989. Sea-ice characterization measurements needed for testing of microwave remote sensing models. IEEE 7. Oceanic Eng., OE-14(2), 149-158.

World Meteorological Organization (WMO). 1970.WMO sea-ice nomenclature: terminology, codes and illustrated glossary. Geneva, Secretariat of the World Meteorological Organization. (WMO/OMM/BMO Report 259, TP 145.) 